\title{
A comparison of a patient-rated visual analogue scale with the Liebowitz Social Anxiety Scale for social anxiety disorder: A cross-sectional study
}

\author{
Hiromi Okitsu ${ }^{1}$, Jitsuki Sawamura ${ }^{1}$, Katsuji Nishimura ${ }^{1}$, Yasuto Sato ${ }^{2}$, Jun Ishigooka $^{1}$ \\ ${ }^{1}$ Department of Psychiatry, Tokyo Women's Medical University, Tokyo, Japan \\ ${ }^{2}$ Department of Hygiene and Public Health II, Tokyo Women's Medical University, Tokyo, Japan \\ Email: okitsu.hiromi@twmu.ac.jp, sawamura.jitsuki@twmu.ac.jp, nishimura.katsuji@twmu.ac.jp, \\ yasusato@research.twmu.ac.jp, ishigooka.jun@twmu.ac.jp
}

Received 15 November 2013; revised 10 December 2013; accepted 17 December 2013

Copyright (c) 2014 Hiromi Okitsu et al. This is an open access article distributed under the Creative Commons Attribution License, which permits unrestricted use, distribution, and reproduction in any medium, provided the original work is properly cited. In accordance of the Creative Commons Attribution License all Copyrights (c) 2014 are reserved for SCIRP and the owner of the intellectual property Hiromi Okitsu et al. All Copyright (C) 2014 are guarded by law and by SCIRP as a guardian.

\section{ABSTRACT}

Introduction: The Liebowitz Social Anxiety Scale (LSAS), used to assess the severity of social anxiety disorder (SAD), requires considerable effort and time to complete. The aims of this study were: 1) to investigate whether a visual analogue scale (VAS) could be linear with the LSAS and substitute for the LSAS, 2) to relate such a VAS instrument to patient demographics. Methods: Fifty SAD patients were assessed using the LSAS and VAS instruments completed by both patients and doctors at the same session. We then drew distributions and calculated the Spearman's $\rho$ and $\boldsymbol{\kappa}$ coefficient values (divided at the median for each scale) between patient and doctor assessments. Next, each pair among the scores for the LSAS, the patient VAS and the doctor VAS was compared using Wilcoxon rank sum tests according to patient life profile data. Results: Scatter plots of pairs of scores were obtained. Spearman's $\rho$ was 0.661 between the LSAS and the patient VAS, 0.461 between the LSAS and the doctor VAS, and 0.494 between VAS scores of patients and doctors. The $\boldsymbol{\kappa}$ coefficients were 0.501 between the LSAS and patient VAS, 0.251 between the LSAS and doctor VAS, and 0.425 between patient VAS and doctor VAS (for all six, $p<0.001)$. The Wilcoxon rank sum tests indicated a significant difference between the groups with/ without “employment" (LSAS, patient/doctor VAS), with/without "graduation from junior college/university” (doctor VAS) (p < 0.05) and with/without marital history (the age of first consultation) (p < 0.01). Conclusions: A patient VAS may substitute for the LSAS and offer the versatility necessary to cap- ture patient states and life profiles.

\section{KEYWORDS}

Social Anxiety Disorder; Visual Analogue Scale;

Kappa Coefficient; Spearman Rank Correlation Coefficient; Wilcoxon Rank Sum Tests;

Patient Demographics

\section{INTRODUCTION}

Social phobia or Social Anxiety Disorder (SAD) is a serious mental disorder characterized by a number of symptoms. Currently, the Liebowitz Social Anxiety Scale is frequently used to assess the severity of patients with social phobia [1], generating a 24-item score for the last week. These items cover the two aspects of social interaction and performance/observation situations, e.g., "Telephoning in public" and "Participating in small groups", respectively. The sum of the scores in each domain expresses the overall severity. The reliability and validity of the LSAS have been extensively examined by many psychiatrists and the credibility of the LSAS has been supported [2-4]. However, in our experience, we often encounter the situation where the total score of the LSAS differs widely from our simple impression of the severity of a patient's social phobia. In addition, the effort and time required to complete it may exceed the capacity of some patients. We also sometimes encounter situations where the characteristics of disease states are quite different from each other although patients may have almost the same score. Not only that, there are situations where there is a discrepancy between the assessment performed by the doctor and that by the patient. In 
the last type of situation, it may be important to find out what background tendencies or relationships are seen in certain patients with social phobia and be able to relate them to the above two aspects (symptoms levels in social interaction and performance/observation situations). To express an overall impression for the severity of illness, a number of well-known scales are used. The Clinical Global Impression of Severity for psychiatric disease [5], specifically, the CGI-SCH for schizophrenia [6], CGI-BP for bipolar illness [7], and CGI for social anxiety disorder [8], gives a score ranging from 1 to 7 in an ordinal scale. Visual analogue scales (VAS) are used to express the value of the total impression for the severity of illness (usually pain) by patients by making a mark determining a decimal number from 0 to 100 (mm) [9-12]. Numerical rating scales (NRS) are also utilized to display the value of the total impression for the severity of illness (usually pain) in a similar manner by determining an integer number from 0 to $10[13,14]$ to substitute for the doctor's/patient's impression (although the true estimation of the validity of both VAS and NRS is in flux at present [15-21]).

Single-item VAS scales have been used in psychological assessment since the early 20th century and have subsequently been employed successfully in the assessment of a wide variety of health-related constructs including pain [22-24], quality-of-life [25,26], mood $[27,28]$, and anxiety [29-33]. VAS scales are brief and simple to administer and minimal in terms of respondent burden.

Until now, to our knowledge, there has been no report on providing an overall impression of SAD severity with VAS scale scores (either rated by patients for themselves or for patients rated by doctors) and of comparing these with LSAS scores. Evaluation scales that are relevant, quick, user-friendly, and graduated at equal intervals are needed to facilitate measurement-based treatment of social phobia. If the use of such VAS scales demonstrates a valid relationship with the LSAS, we might obtain another approach to assessing the characteristics of the differing disease states of social anxiety disorder simply and quickly. In addition, if there is a relationship between them, it might be possible to feed these results back to clinical treatment and research on SAD. It may also be possible to assess whether there are associations between the profiles of patients (e.g., male/female, with/without occupations, educational backgrounds, with/without cohabiters).

The aims of this study were two-fold: 1 ) to investigate whether a VAS could be in a good linear relationship with the LSAS, such that there is a possibility that the VAS could be versatile enough to substitute for the LSAS, even if only partially, 2) to study how such a patient VAS score is associated with patient life profiles (e.g., sex, with/without occupations, educational back- grounds, with/without cohabiters). However, this was only a pilot study, and our main aims were to present a viewpoint and an approach that future studies would re-investigate and develop with more rigor.

\section{METHODS}

The LSAS is a 24-item scale that measures fear and/or anxiety and avoidance of social situations over the last week. It consists of 11 items relating to social interaction and 13 items related to public performance. Each item is rated $0,1,2$ or 3 both for fear/anxiety and for avoidance, with the score for each item being the sum of the two parts and the total score for the LSAS being the sum of all 24 items. Our hypothesis was that the VAS score would have meaning as an indicator of the degree of severity for SAD.

\subsection{Participants}

This is a prospective study of outpatients treated at the Tokyo Women's Medical University Hospital, and Tokyo Women's Medical University, Medical Center East, who met the DSM-IV-TR [34] criteria for SAD. A total of 50 patients (23 males, 27 females) with mean age of $35.18 \pm$ 12.05 years (range, 18 - 73) were included in this study as a convenience sample between 26 January 2012 and 4 July 2012. The present study was approved by the ethics committee of Tokyo Women's Medical University, and all patients signed informed consent forms before participating in the study.

\subsection{Research Design}

For these patients, the evaluations for SAD were performed by the patients and by sixteen experienced doctors independently (with patients and doctors blind to each other's ratings) at the same session. The evaluation scales used in the study are "patient VAS" (evaluated by patients themselves in terms of their state, e.g., like Figure 1), “doctor VAS” (evaluated by doctors in terms of the patient's state), and the LSAS completed by patients. At the same time, patient profiles and demographic information were collected, including age, sex, with/ without cohabiters, educational background, marital history, employment status, year of first consultation, and

Note how severe you feel your disease state is with a mark () on the line below.

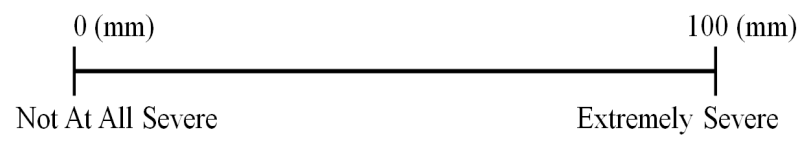

Figure 1. The visual analogue scale. The degree of severity of the anxious disease state was marked within the range of 0 100 (mm) by patients. A similar scale was also used by doctors to rate patients. 
year of onset. Our intention was to compare the scores between the LSAS and the patient VAS (rated by patients themselves), then between the LSAS and the doctor VAS, and finally between the patient VAS and the doctor VAS. We drew the scatter plot for all pairs of individual scores and calculated Spearman's $\rho$ using raw data and $\kappa$ coefficients with cross tabulations divided at the medians of both the LSAS (72 points) and the VAS (50 points) for each pair (LSAS and patient VAS, LSAS and doctor VAS, patient VAS and doctor VAS).

After that, for all patients, basic demographic statistical data were displayed to survey for trends in terms of "age", "sex", "existence of marital history", "existence of cohabiters", "employment", "graduation of junior college or university", "the year of onset", and "the age of first consultation (years)". Additionally, Wilcoxon rank sum tests between age, sex, existence of marital history, existence of cohabiters, employment status, graduation of junior college or university, the age of onset, and the age of first consultation were performed to examine for specific differences. We used SPSS for Windows, version 20 [35] for statistical analysis, Stata Release 10.0 [36] to draw scatter plots, and Microsoft Excel 2003 [37] for formatting the files.

\section{RESULTS}

The scatter plots between all pairs of individual scores for all 50 patients are shown in Figure 2. In Table 1, the Spearman's $\rho$ between the LSAS and patient VAS scores is 0.661 ( $p<0.001)$, while that between the LSAS and doctor VAS scores is $0.461(\mathrm{p}<0.001)$, and that between patient and doctor VAS scores is 0.494 ( $\mathrm{p}<0.001)$. In Table 2, $\kappa$ coefficients between each pair of two scales are shown. Between the LSAS and patient VAS, the $\kappa$ was $0.501(\mathrm{p}<0.001)$, while it was $0.251(\mathrm{p}<0.001)$ between the LSAS and doctor VAS scores and 0.425 (p $<0.001$ ) between the patient and doctor VAS scores. For all 50 patients, mean scores for the LSAS were $76.00 \pm$ 28.53 (S.D.), while for the patient VAS and the doctor VAS, they were $52.58 \pm 26.26$ (S.D.) and $52.14 \pm 25.48$ (S.D.), respectively. Basic patient demographic profiles are presented in Table 3. The Wilcoxon rank sum tests for patient demographics showed significant differences between the group with/without "employment" (LSAS, patient and doctor VAS), with/without "graduation of junior college/university" (doctor VAS) $(\mathrm{p}<0.05)$ and with/without "marital history" (the age of first consultation) $(\mathrm{p}<0.01)$ in Table 4, although the reproducibility is ambiguous at this stage because of our small sample data size.

\section{DISCUSSION}

This study was performed not only to examine the value

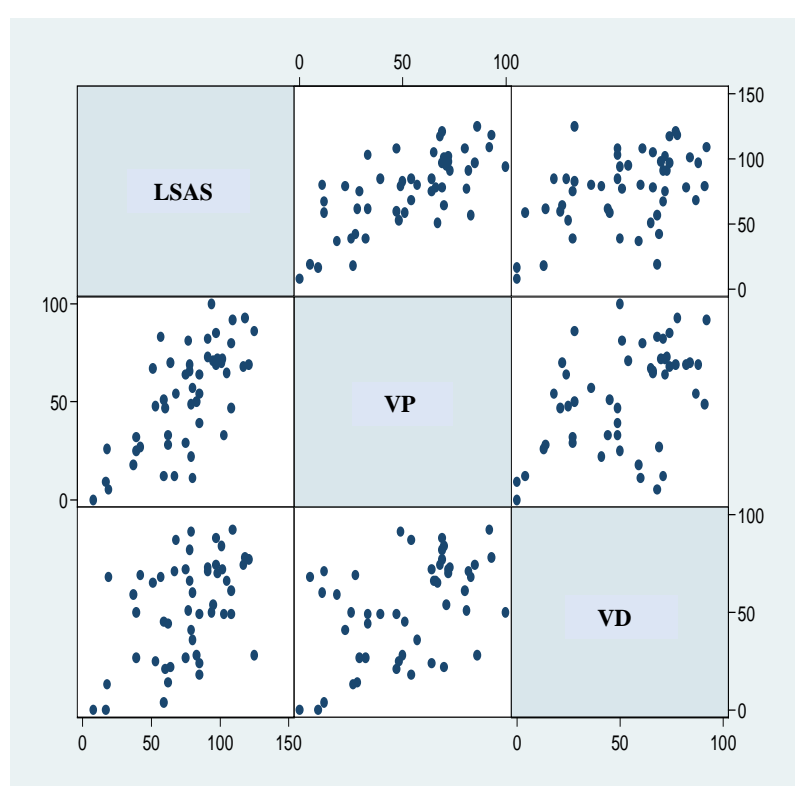

Figure 2. Scatter plots for each pair of scales. The scatter plots between any pair of the scales among the LSAS, VAS rated by patients (denoted VP), and VAS rated by patients' doctors (denoted VD) are presented (the mirror images are also illustrated). Abbreviations; VP: visual analogue scale (VAS) rated by patients, VD: VAS rated by doctors.

Table 1. Spearman's $\rho$ between the two scales.

\begin{tabular}{cccc}
\hline & LSAS & VP & VD \\
\hline LSAS & 1 & & \\
VP & 0.661 & 1 & \\
VD & 0.461 & 0.494 & 1
\end{tabular}

Abbreviations: VP: visual analogue scale (VAS) rated by patients; VD: VAS rated by doctors. Spearman's $\rho$ values expressing the degree of correlation between each pair (LSAS, patient VAS, doctor VAS) are presented.

Table 2. $\kappa$ coefficient between the two scales.

\begin{tabular}{cccc}
\hline & LSAS & VP & VD \\
\hline LSAS & 1 & & \\
VP & 0.501 & 1 & \\
VD & 0.251 & 0.425 & 1 \\
\hline
\end{tabular}

Abbreviations: VP: visual analogue scale (VAS) rated by patients; VD: VAS rated by doctors. The $\kappa$ coefficients, expressing the degree of accordance between each pair among 1) LSAS and patient VAS, 2) LSAS and doctor VAS, and 3) patient VAS and doctor VAS, are presented.

of a VAS scale for SAD but also to clarify the characteristics of the LSAS. The LSAS scale has been well- studied [2-4] and our qualitative results demonstrated that SAD patients had no difficulties with the VAS format or with reporting global anxiety levels. Similar methods have been used in anesthesiology, [38,39] where the study was based on average pain levels over the last 24 hours. Unexpectedly, to our knowledge, for severity of anxiety, no study has reported on VAS scales rated by patients for themselves and for patients by doctors at the 
Table 3. Essential data of patients' life profiles and results of Wilcoxon rank sum tests.

\begin{tabular}{|c|c|c|c|}
\hline $\begin{array}{l}\text { Life profiles } \\
\text { of patients }\end{array}$ & $\begin{array}{c}\text { Total } \\
(\mathrm{n}=50)\end{array}$ & Category & $\begin{array}{l}\text { Significance } \\
\text { for scale }\end{array}$ \\
\hline Age (years) & $\begin{array}{c}\text { Mean } \pm \text { S.D. } \\
35.18 \pm 12.05\end{array}$ & & \\
\hline Male/Female & $(\mathrm{n}=50)$ & $\begin{array}{l}46 \%(\mathrm{n}=23) / \\
54 \%(\mathrm{n}=27)\end{array}$ & n.s. \\
\hline $\begin{array}{l}\text { Existence of } \\
\text { marital history/not }\end{array}$ & $(\mathrm{n}=50)$ & $\begin{array}{l}28 \%(\mathrm{n}=14) / \\
72 \%(\mathrm{n}=36)\end{array}$ & n.s. \\
\hline $\begin{array}{l}\text { Existence of } \\
\text { cohabiters/not }\end{array}$ & $(\mathrm{n}=50)$ & $\begin{array}{c}84 \%(\mathrm{n}=42) / \\
16 \%(\mathrm{n}=8)\end{array}$ & n.s. \\
\hline Employment/not & $(\mathrm{n}=50)$ & $\begin{array}{l}36 \%(\mathrm{n}=18) / \\
64 \%(\mathrm{n}=32)\end{array}$ & $\begin{array}{c}\mathrm{s}^{*} \\
\text { (patient/doctor) }\end{array}$ \\
\hline $\begin{array}{l}\text { Graduation of } \\
\text { short college or } \\
\text { university/not }\end{array}$ & $(\mathrm{n}=50)$ & $\begin{array}{l}42 \%(\mathrm{n}=21) / \\
58 \%(\mathrm{n}=29)\end{array}$ & $\mathrm{s}^{*}$ (doctor) \\
\hline
\end{tabular}

$\mathrm{s}^{*}$ : significance for VAS $(\mathrm{p}<0.05), \mathrm{s}^{* *}$ : significance for VAS $(\mathrm{p}<0.01)$, n.s.: non-significance for VAS ( $\mathrm{p} \geq 0.05)$ Abbreviations: VP: visual analogue scale (VAS) rated by patients; LSAS: Liebowitz Social Anxiety Scale. The essential data of patient life profiles (e.g., age, sex, existence of marital history.) are presented for 50 patients. There was a significant difference between with/without employment (LSAS, patient/doctor VAS) and with/ without graduation of junior college or university (doctor VAS) $(p<0.05)$.

Table 4. The results of Wilcoxon rank sum tests.

\begin{tabular}{cccc}
\hline & $\begin{array}{c}\text { Total } \\
(\mathrm{n}=50)\end{array}$ & $\begin{array}{c}\text { Marriage }(\mathrm{n}=14) \\
/ \text { not }(\mathrm{n}=36)\end{array}$ & \\
\hline $\begin{array}{c}\text { The age of } \\
\text { onset (years) }\end{array}$ & $19.86 \pm 9.61$ & $24.21 \pm 12.72 /$ & n.s. \\
& & $18.17 \pm 7.66$ & \\
$\begin{array}{c}\text { The age of first } \\
\text { consultation (years) }\end{array}$ & $27.00 \pm 8.63$ & $33.93 \pm 7.24 /$ & s** \\
\hline
\end{tabular}

$\mathrm{s}^{*}$ : significance for years $(\mathrm{p}<0.05), \mathrm{s}^{* *}$ : significance for years $(\mathrm{p}<0.01)$, n.s.: non-significance for years $(\mathrm{p} \geq 0.05)$. There was a significant difference for first consultation (years) with/without marital history $(\mathrm{p}<0.01)$.

same session being compared with the LSAS, although VASs are used for pain, especially in anesthesiology, $[12,13,38,39]$ and in some cases, dentistry [32]. In the psychiatric field, the Clinical Global Impression-Severity scale (CGI-S), for example, with schizophrenia (CGISCH), is usually used in daily clinical practice [5-8]. However, the consistency of calibration of these scales has not been proven. Furthermore, the CGIs are rated only by doctors while the VASs are ordinarily rated by patients themselves; in our view, both raters should be using the same-ranged/same-formed scale. The first reason that we focused on the VAS was that we expected the VAS score to better reflect the patient's genuine impression in a linear way. The second reason was that we considered the comparisons of patient-rated with doctorrated VAS and of the patient-rated VAS with the LSAS necessary to most accurately assess the true severity of the patients' disease states. As shown in the Results section, there are good correlations between the LSAS and the patient VAS, although there may exist biases because of the small sample size of the data. In future, we might be able to substitute the patient VAS for the original LSAS at least in part.

Based on the present study, the VAS score rated by doctors does not seem to have a good linear relationship (either in terms of Spearman's $\rho$ or $\kappa$ coefficient), which might imply that doctors do not always perform a good assessment of patient states, such as severity, and that patients may have a better impression of their own state than their doctors.

The Wilcoxon rank sum tests (Table 3) show that there were significant differences between the patient and doctor VAS for with/without "employment" and "education". However, it is likely that there were potential influential confounder biases on the patients' and doctors' impressions since employment and education imply participation in society. For the age of first consultation, that of patients with "marital history" is higher than that of patients without marital history (Table 4). This suggests that "marital history" is associated with supportive circumstances that could delay the age of first consultation for SAD patients. Whether this will be reproducible is unclear.

Although our findings may not be reproducible, one of our main purposes for this study was to propose a new approach for improving evaluation scales used in daily clinical practice. These often require more time and effort than is feasible for patients who do not have good mental states. We believe that there might be value for this kind of approach in the future.

In summary, the results of the current study suggest that a patient VAS score for SAD could be a substitute option that requires less time and effort for rating patient severity. Doctors might be able to use such patient selfassessments of their disease states for more precise diagnosis and treatment, although further investigations are needed with more rigorous methodology.

The limitations of the present study should be noted. The first was the use of the VAS as a scale that substituted for the evaluation made by the patients (and doctors). There is no evidence that the VAS is a gold standard and that it has perfect linearity with the severity of patients' disease states. The substitution of a patient VAS score is merely a tentative assumption to pursue a method to reduce the time and effort of patients in daily clinical examination. Even with the original VAS, as mentioned before, only a certain degree of reliability has been reported [15-21]. Nonetheless, we thought that this kind of simplification was unavoidable when designing the experiment and that the trade-off was necessary, although this assumption might sacrifice rigor in exchange for a simpler expression of the degree of subjective severity of a mental disease. 
Second, there was no assurance that the assumption that the VAS scores obtained from many doctors had good inter-rater reliability was correct because this was not assessed. The exact reproducibility of the VAS score seems to be low because the values permitted are any real numbers from 0 to 100 , which are infinite, so that the probability that the same score can be obtained even by the same doctor is almost zero. However, the probability that almost the same score can be obtained might be close to that of an eleven-grade scale using $0,1,2,3$, $\cdots, 9,10$ (the Numerical rating scale or NRS $[13,14]$ ). It may be, however, that the score determined freely within this range might be influenced by chance or other contingent factors.

Third, to our knowledge, the use of VAS scales is not established in the psychiatric field. Those supported by literature and statistical analysis are accepted in other fields of medicine such as anesthesiology and dentistry, as mentioned previously. Right from the start, it is unclear what meaning to assign to the score of 100 with the patient VAS. In our literature search, there was no rigorous definition for the highest score 100 for the VAS when applied to mental states. In previous articles using the VAS scale, it is ambiguous whether 100 means "the worst possible anxious disease state that can be imagined" or "the most severe anxious state that is experienced by the patient (or doctor) so far". We presume that one of the outcomes of psychiatric treatment is a subjective impression of patient improvement, such as the VAS rated by the patient (or, in some cases, the VAS rated by their families). Therefore, there may be valid meaning in the range of 0 - 100 even when the meaning of the edges ( 0 or 100 points) is difficult to define concretely. Therefore, a "VAS-I" (VAS for improvement, a scale not currently established) by patients (or their families) might play a role in the future, although such a scale might have other problems, e.g., "reproducibility". For these reasons, the best definitions of the maximum score 100 for a patient VAS will depend upon future study.

Fourth and finally, because a biomarker that indicates quantitative degrees of severity for anxiety has not been detected, evaluation scales such as those in the present article must substitute at present for all patients. If such a biomarker does not exist, degrees of anxiety cannot be quantified objectively and the subjective measures of a study like this could not be correlated and might lose scientific confidence. In our model, a validity analysis of "test-retest reliability" and "internal consistency" (Cronbach's $\alpha$ ) between doctors was not assessed, and so the presence of sufficient reliability and validity in this model might be doubtful at this stage. If we performed the same procedure with new data, it is very likely that different tendencies might be identified. Therefore, the extent to which the results of this paper could be applicable may be limited only to our present data. For this reason, future studies conducted with sufficiently large samples obtained randomly are necessary.

We anticipate that our present results will serve as a useful reference for clinicians attempting to devise an evaluation scale, and that further research will focus on the optimal method with rigorous methodology to investigate the utility of the VAS.

\section{CONCLUSION}

There was a good linear relationship between the LSAS score and patients' global self-impressions (patient VAS score). The LSAS scores and doctors' global impressions (doctor VAS score) were less well-correlated. There may be circumstances where patient VAS scores could substitute for the LSAS to reduce the time and effort for patients. Certain demographic features may be predictive of this, as future studies may show.

\section{ACKNOWLEDGEMENTS}

The authors wish to acknowledge Kaoru Sakamoto and Kazuo Yamada for providing us with very useful advice in this study. None of the authors has any conflict of interest to disclose.

\section{REFERENCES}

[1] Liebowitz, M.R. (1987) Social phobia. Modern Problems of Pharmacopsychiatry, 22, 141-173.

[2] Heimberg, R.G., Horner, K.J., Juster, H.R., et al. (1999) Psychometric properties of the Liebowitz Social Anxiety Scale. Psychological Medicine, 29, 199-212. http://dx.doi.org/10.1017/S0033291798007879

[3] Fresco, D.M., Coles, M.E., Heimberg, R.G., et al. (2001) The Liebowitz Social Anxiety Scale: A comparison of the psychometric properties of self-report and clinician-administered formats. Psychological Medicine, 31, 10251035.

[4] Mennin, D.S., Fresco, D.M., Heimberg, R.G., Schneier, F.R., Davies, S.O. and Liebowitz, M.R. (2002) Screening for social anxiety disorder in the clinical setting: Using the Liebowitz Social Anxiety Scale. Journal of Anxiety Disorders, 16, 661-673. http://dx.doi.org/10.1016/S0887-6185(02)00134-2

[5] Guy, W. (1976) ECDEU Assessment manual for psychopharmacology. Rev. Edn. US Department of Health, Education, and Welfare (ADM) 76-338.: National Institute of Mental Health, Rockville, 218-222.

[6] Haro, J.M., Kamath, S.A., Ochoa, S., et al. (SOHO Study Group) (2003) The clinical global impression-schizophrenia scale: A simple instrument to measure the diversity of symptoms present in schizophrenia. Acta Psychiatrica Scandinavica, 107, 16-23. http://dx.doi.org/10.1034/j.1600-0447.107.s416.5.x

[7] Spearing, M.K., Post, R.M., Leverich, G.S., Brandt, D. and Nolen, W. (1997) Modification of the Clinical Global 
Impressions (CGI) Scale for use in bipolar illness (BP): The CGI-BP. Psychiatry Research, 73, 159-171. http://dx.doi.org/10.1016/S0165-1781(97)00123-6

[8] Zaider, T.I., Heinberg, R.G., Fresco, D.M., et al. (2003) Evaluation of the clinical global impression scale among individual with social anxiety disorder. Psychological Medicine, 33, 611-622. http://dx.doi.org/10.1017/S0033291703007414

[9] Hayes, M.H.S. and Patterson, D.G. (1921) Experimental development of the graphic rating method. Psychological Bulletin, 18, 98-99.

[10] Freyd, M. (1923) The graphic rating scale. Journal of Educational Psychology, 14, 83-102. http://dx.doi.org/10.1037/h0074329

[11] Crichton, N. (2001) Information point: Visual Analogue Scale (VAS). Journal of Clinical Nursing, 10, 697-706.

[12] Langley, G.B. and Sheppeard, H. (1985) The visual analogue scale: Its use in pain measurement. Rheumatology International, 5, 145-148. http://dx.doi.org/10.1007/BF00541514

[13] Turk, D.C., Rudy, T.E. and Sorkin, B.A. (1993) Neglected topics in chronic pain treatment outcome studies: Determination of success. Pain, 53, 3-16. http://dx.doi.org/10.1016/0304-3959(93)90049-U

[14] Farrar, J.T., Young, J.P. Jr., LaMoreaux, L., Werth, J.L. and Poole, R.M. (2001) Clinical importance of changes in chronic pain intensity measured on an 11-point numerical pain rating scale. Pain, 94, 149-158. http://dx.doi.org/10.1016/S0304-3959(01)00349-9

[15] Price, D.D., McGrath, P.A., Rafii, A. and Buckingham, B. (1983) The validation of visual analogue scales as ratio scale measures for chronic and experimental pain. Pain, 17, 45-56. http://dx.doi.org/10.1016/0304-3959(83)90126-4

[16] Dixon, J.S. and Bird, H.A. (1981) Reproducibility along a $10 \mathrm{~cm}$ vertical visual analogue scale. Annals of the Rheumatic Diseases, 40, 87-89. http://dx.doi.org/10.1136/ard.40.1.87

[17] Maxwell, C. (1978) Sensitivity and accuracy of the visual analogue scale: A psycho-physical classroom experiment. British Journal of Clinical Pharmacology, 6, 15-24. http://dx.doi.org/10.1111/j.1365-2125.1978.tb01676.x

[18] Grunberg, S.M., Groshen, S., Steingrass, S., Zaretsky, S. and Meyerowitz, B. (1996) Comparison of conditional quality of life terminology and visual analogue scale measurements. Quality of Life Research, 5, 65-72. http://dx.doi.org/10.1007/BF00435970

[19] Hartrick, C.T. and Kovan, J.P. (2003) The numeric rating scale for clinical pain measurement: A ratio measure? Pain Practice, 3, 310-316. http://dx.doi.org/10.1111/j.1530-7085.2003.03034.x

[20] DeLoach, L.J., Higgins, M.S., Caplan, A.B. and Stiff, J.L. (1998) The visual analog scale in the immediate postoperative period: Intrasubject variability and correlation with a numeric scale. Anesthesia and Analgesia, 86, 102106.

[21] Myles, P.S., Troedel, S., Boquest, M. and Reeves, M. (1999) The pain visual analog scale: Is it linear or nonli- near? Anesthesia and Analgesia, 89, 1517-1520.

[22] Bruera, E., Kuehn, N., Miller, M.J., Selmser, P. and Macmillan, K. (1991) The Edmonton Symptom Assessment System (ESAS): A simple method for the assessment of palliative care patients. Palliative Care, 7, 6-9.

[23] Kremer, E., Atkinson, J.H. and Ignelzi, R.J. (1981) Measurement of pain: Patient preference does not confound pain measurement. Pain, 10, 241-248. http://dx.doi.org/10.1016/0304-3959(81)90199-8

[24] Scott, J. and Huskisson, E.C. (1976) Graphic representation of pain. Pain, 2, 175-184. http://dx.doi.org/10.1016/0304-3959(76)90113-5

[25] deBoer, A.E.M., van Lanschot, J.J.B., Stalmeier, P.F.M., et al. (2004) Is a single-item visual analogue scale as valid, reliable and responsive as multi-item scales in measuring quality of life? Quality of Life Research, 13, 311320.

http://dx.doi.org/10.1023/B:QURE.0000018499.64574.1f

[26] Hyland, M.E. and Sodergren, S.C. (1996) Development of a new type of global quality of life scale, and comparison of performance and preference for 12 global scales. Quality of Life Research, 5, 469-480. http://dx.doi.org/10.1007/BF00540019

[27] Lingjaerde, O. and Foreland, A.R. (1998) Direct assessment of improvement in winter depression with a visual analogue scale: High reliability and validity. Psychiatry Research, 81, 387-392. http://dx.doi.org/10.1016/S0165-1781(98)00119-X

[28] Steiner, M. and Streiner, D.L. (2005) Validation of a revised visual analog scale for premenstrual mood symptoms: Results from prospective and retrospective trials. Canadian Journal of Psychiatry, 50, 327-332.

[29] Mortimore, C. and Anderson, I.M. (2000) d-Fenfluramine in panic disorder: A dual role for 5-hydroxytryptamine. Psychopharmacology, 149, 251-258. http://dx.doi.org/10.1007/s002139900342

[30] Hornblow, A.R. and Kidson, M.A. (1976) The visual analogue scale for anxiety: A validation study. Australia and New Zealand Journal of Psychiatry, 10, 339-341. http://dx.doi.org/10.3109/00048677609159523

[31] Gift, A.G. (1989) Visual analogue scales: Measurement of subjective phenomena. Nursing Research, 38, 286288.

http://dx.doi.org/10.1097/00006199-198909000-00006

[32] Zaitsu, T., Ueno, M., Shinada, K., Wright, F.A. and Kawaguchi, Y. (2011) Social anxiety disorder in genuine halitosis patients. Health and Quality of Life Outcomes, 9, 94. http://dx.doi.org/10.1186/1477-7525-9-94

[33] Williams, V.S.L., Morlock, R. and Feltner, D. (2010) Psychometric evaluation of a visual analogue scale for the assessment of anxiety. Health and Quality of Life Outcomes, 8, 57. http://dx.doi.org/10.1186/1477-7525-8-57

[34] American Psychiatric Association (2000) Diagnostic and statistical manual of mental disorders. 4th Edition, Text Revision, American Psychiatric Publishing, New York.

[35] SPSS Inc. (2011) SPSS for Windows Version 20. SPSS Inc., Armonk. 
[36] Stata Corporation (2007) Stata user's guide, release 10.0. Stata Corporation, College Station.

[37] Microsoft Corporation (2003) Microsoft Excel 2003. Microsoft Corporation, Redmond.

[38] Scrimshaw, S.V. and Maher, C. (2001) Responsiveness of visual analogue and McGill pain scale measures. Journal of Manipulative and Physiological Therapeutics, 24, 501504. http://dx.doi.org/10.1067/mmt.2001.118208

[39] Melzack, R. (2005) The McGill pain questionnaire: From description to measurement. Anesthesiology, 103, 199202.

http://dx.doi.org/10.1097/00000542-200507000-00028 